\title{
ORALIDADE E LINGUA POPULAR NA CONSTRUCIÓN DUN REXISTRO LITERARIO EN CANTARES GALLEGOS
}

Xosé A. Fernández Salgado

Universidade de Vigo

doi. 10.17075/rcsxxi.2014.009

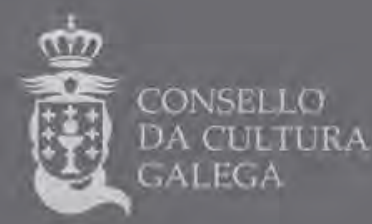



Álvarez, R. / A. Angueira / M. C. Rábade / D. Vilavedra (coords.) (2014): Rosalía de Castro no século XXI. Unha nova ollada, Santiago de Compostela, Consello da Cultura Galega. doi:10.17075/rcsxxi.2014. pp. 157-180

\section{INTRODUCIÓN}

Nun xa clásico traballo sobre o galego de Rosalía de Castro, Carballo Calero (1972: 7-9) salientaba naquela altura que así como xa entón había unha considerable bibliografía sobre a vertente literaria da súa obra, os investigadores amosaran unha escasa preocupación científica sobre o galego usado por parte da escritora; e achacaba iso a que os estudosos consideraran que Rosalía empregaba «un mal gallego» e que non pagaba a pena «estudiar la lengua de Rosalía, porque Rosalía no es autoridad en la lengua» porque o seu galego «ni es puro ni es coherente».

Esa pioneira investigación de Carballo Calero sobre as particularidades morfolóxicas da linguaxe de Rosalía foi continuada logo por outros investigadores que en varios aspectos foron completando a caracterización do galego literario rosaliano. Sen dúbida, destacan os traballos presentados no Congreso Internacional de Estudios sobre Rosalía de Castro e o seu Tempo, que en 1985 lembrou o centenario da morte da poeta. O tomo III das súas Actas (1986) contén varios capítulos sobre o galego usado na obra rosaliana, entre os que salientan o de Lorenzo (1986), sobre a lingua literaria daquel tempo; o de Pensado (1986), no que comenta varias voces contidas no "Glosario» final de Cantares gallegos; o de Mackenzie (1986), que aborda dun xeito sintético a variación de formas dun mesmo termo nos dous poemarios en galego de Rosalía; o de Xove (1986), que analiza a alternancia e valores das formas verbais do antepretérito en -ra e do pretérito de subxuntivo en -se nestes mesmos libros; o de Abuín González / Azaustre Galiana (1986), sobre a presenza do seseo na súa obra; ou os de García (1986), Brea (1986) e González (1986), que describen diferentes aspectos léxicos relativos á presenza de animais nos versos da poeta. De 1986 é tamén a memoria de licenciatura inédita de Álvarez Ruiz de Ojeda (1986), na que analiza aspectos gráficos, fonéticos, morfolóxicos e castelanismos en Cantares gallegos e Follas novas; e de 1987, o amplo estudo léxico destes poemarios por parte de García (1987). Da década dos noventa, son as análises lingüísticas de Monteagudo / Vilavedra (1993) e de Lama (1995), contidas nas introducións das súas edicións 
de Follas novas e Cantares gallegos, respectivamente ${ }^{1}$; e tamén o capítulo que Freixeiro Mato (1996) dedicou ó estudo do diminutivo na poesía rosaliana dentro da súa monografía sobre a sufixación apreciativa.

En todas esas análises xa aparecen deliñados os principais trazos que caracterizan a lingua literaria rosaliana: isto é, unha lingua modelada a partir do galego oral falado polos paisanos santiagueses de mediados do século XIX. Sendo así, a lingua das súas obras non pode espellar senón un galego popular, sobre todo a de Cantares gallegos. Así o viron tamén Alonso Montero (1970: 38), cando afirmou que Rosalía escribía como falaba; Carballo Calero (1974: 35-37), que na súa periodización da lingua literaria incluíu Cantares na etapa do "galego dialectal»; ou anos máis tarde Fernández Salgado / Monteagudo (1995), que caracterizaron a súa lingua como pertencente ó que chaman «galego popularista».

$\mathrm{Na}$ seguinte exposición imos caracterizar os trazos lingüísticos que clasifican a lingua de Cantares gallegos (1863) ${ }^{2}$, o libro auroral do Rexurdimento galego que cumpre os 150 anos da súa publicación, como de rexistro popular. Así e todo, cómpre ter en conta que sobre o pouso dese galego oral e popular destilan en moitos versos formas e estruturas lingüísticas de rexistro literario máis formal, tomadas unhas veces da nosa tradición literaria oral, outras das literaturas escritas veciñas, e mesmo ecoan tamén algúns trazos arcaizantes ${ }^{3}$.

\section{VARIACIÓN E POLIMORFISMO EN CANTARES GALLEGOS}

O galego entrou no século xIx sendo unha lingua eminentemente falada, circunscrita ó ámbito familiar e rural, xa que nos séculos precedentes fora desprazado dos rexistros cultos e escritos polo castelán, o que lle impedira no tránsito da época medieval á moderna habilitar un sistema gráfico, gramatical e léxico

1 Cando este artigo xa estaba pechado, A. Angueira publicou a súa edición de Cantares gallegos (2013, Ed. Xerais), que contén, amais dun longo estudo introdutorio (p. 9-114), un rigoroso aparello de notas (p. 307-444) que comentan polo miúdo moitos aspectos lingüísticos da obra.

2 Nos exemplos da análise seguimos fundamentalmente o texto da $2^{a}$ edición ampliada, feita en 1872.

3 Por razóns de espazo, nesta contribución centrámonos na descrición dos trazos orais e populares máis destacados de Cantares. En breve publicaremos outro traballo que completa esta análise con aspectos sobre as formas e estruturas de rexistros máis formais, a compońente dialectal e os castelanismos. 
uniforme, estable e coherente, que si puideran facer dun xeito normal os outros idiomas veciños.

Por iso, libre dos moldes e regras normativas das linguas codificadas, o galego oral de mediados do século xix, ateigado de entoacións enfáticas, pronuncias populares, voces coloquiais, formas dialectais e mesmo castelanismos, ese galego «sin gramática nin regras de ningunha clás»-como se di no Prólogo de Cantares-, amósase a Rosalía como unha lingua tremendamente flexible, variada, espontánea, aberta, natural... coa que poder experimentar poeticamente, o que sen dúbida acabou traducíndose nunha das características máis salientables do galego rosaliano: a variación de formas nos distintos niveis lingüísticos.

Por pońermos algúns exemplos de Cantares, hai variación gráfica no uso das grafías: avós / abó ('avó'), botar / votar ('botar'), baixa / vaixa ('baixa'), revolvía / rebolvía ('revolver'), vaite / baite (de 'ir'), valado / balado ('valado'), vello / bello ('vello'), aya / haya ('haxa'), hoxe / oxe ('hoxe'), ora / hora ('ora'), achara / hachara ('achar'), extrañeza / estraneza ('estrañeza'), igrexa / ygrexa ('igrexa'), vai / vay ('vai'), coraçon / corason / corazon ('corazón)...; na acentuación: quedara / quedára ('quedara'), terra / térra ('terra'), pé / pe ('pé'), é / e (de 'ser')...; na delimitación de palabras: abofe / a bofe ('abofé'), des que / desque ('des que')...; ou na representación de elisións, contraccións e asimilacións da lingua oral con apóstrofos e guións: pó lo / po-lo ('por+o'), do / d' o / d' ó / dó ('de+o'), tódolos / todo-los ('todos os'), non hay / n' ei / né / no-no ('non hai', 'non hei', 'non é, 'non o', respectivamente), etc.

Esta impresión de anarquía gráfica que irradia Cantares e, en xeral, os outros textos oitocentistas galegos é habitual na escrita de calquera lingua que estea nos inicios da súa codificación gráfica, como é o caso do libro de Rosalía. Ante a falta dunha autoridade lingüística, cada autor fai a súa propia proposta, o que á fin se transloce en diverxencias entre eles; e mesmo poligrafismo dentro da obra do propio escritor, coma no caso de Cantares. Rosalía é consciente diso cando se 
escusa no Prólogo de que non habendo regras «ó lector topará moitas veces faltas d' ortografía, xiros que disoarán ôs oidos d' un purista» ${ }^{4}$.

Por outra banda, existe tamén variación fónica de vogais: suspira / sospira, desperta / disperta, ningún / nengún, adereso / adreso, amor / amore, traen / trân...; e de consoantes: cabeza / cabeça..., floriñas / froriñas..., primeiro / pirmeiro... Dáse, igualmente, alternancia morfolóxica na formación dos plurais: aqueles / aquês, salons / espresiós...; nos radicais e desinencias verbais: puxo / puñeches, poidera / pudera, morreche / quentastes...; e nas terminacións e sufixacións nominais: verdade / verdá / verdad, soberbia / soberba, amabre / miserable, silencio / espaço... Atopamos tamén variantes sintácticas: por te contemplar / por darlle, en tódalas partes / en todas as partes, como / coma comparativos + verbo, onde / onda relativos + verbo... E, por suposto, existe variación léxica, na cal sobrancean as alternancias entre as voces galegas e as interferidas polo castelán (fermosa / hermosa, lua / luna, centeo / centeno, limpo / limpio, salgado / salado, soidades / soidá / soledades / soledá, esquencida / olvidada, carballal / robreda...

A variatio é algo apreciado no estilo dun autor co fin de que deleite sen repetir, e Rosalía aproveitou a flexibilidade e diversidade de formas que lle ofrecía o galego popular como un recurso estilístico máis en caso de lle querer imprimir ritmo ó poema, de ter que cadrar a medida duns versos, de facer que rimen ou doutros valores expresivos que se nos escapan. Neste punto, a poeta non dubidará en someter o lingüístico ó literario, ben que iso a leve a usar un castelanismo, a botar man dun vulgarismo ou, mesmo, a mudar a morfoloxía ou a pronuncia dunha palabra.

Por poñermos algunhas mostras desa variación, a alternancia no poema 1 entre carballo e o castelanismo robre vén dada polas palabras coas que riman: robres con fontes, e carballo con orballo. Igualmente, é ben coñecida a invención da forma fertunha, con nasal velar, para que rime con unha e ningunha na estrofa XXVII do poema 25. Así mesmo, a escolla no poema 29 das formas parese / parece, en

4 Para quen estea familiarizado con textos manuscritos do século XIX non sorprenderá indicar que faltas de ortografía (dende a óptica actual) habíaas tanto no galego coma no castelán, e non só en Rosalía, senón tamén noutros autores. Naya Pérez (1953: 68) alude ás daquela cando falando dunhas notas que transcribe di: «Aquí las aliviamos de sus faltas de ortografía». Por outra parte, na súa edición de Cantares, Pociña / López (1993: XLVIII-L) xustifican o seu respecto ás variacións ortográficas e morfolóxicas e mais ás formas duplas porque coidan que a poeta eran consciente delas e ademais fan parte do estilo da súa escrita. 
estrofas contiguas, pode vir motivada por algunha razón estilística, segundo a cal a forma seseante denotaría máis expresividade e afectividade (parese / rosa) cá ceceante (parece / repolo). Ou, en fin, no poema 32 son tamén razóns de rima as que levan a Rosalía a inventar un segunda persoa do singular do futuro de subxuntivo do verbo querer como quixerde, á imaxe da de plural pero sen $-s$ (quixerdes), para así rimar con verde e perde.

En definitiva, Rosalía aproveitou en Cantares gallegos a menor fixación gramatical dunha lingua popular coma o galego para ensaiar coas distintas variantes posibles efectos estilísticos que quizais outras linguas máis formalizadas non lle poderían ofrecer; ben que, por outra banda, o uso de moitas desas formas populares viñan xustificadas estilisticamente polo tipo de poemario que era: en aparencia, un libro de glosas de cantares do pobo.

\section{OS ESTILOS LINGÜÍSTICOS DE CANTARES GALLEGOS}

O patrón lingüístico de Cantares gallegos é o do galego popular falado naquela altura polas terras de Santiago e da veiga de Padrón. En certo modo, o popular era o único modelo que posuían ou coñecían non só Rosalía senón os outros precursores do Rexurdimento galego: a prestixiosa lírica medieval galega era practicamente descońecida e os escasos textos literarios que precederon os Cantares non deran conseguido carta de «clásicos». Carballo Calero (1972: 13) chega a afirmar que Rosalía en Cantares «produce la impresión de que no había leído nada en gallego", que se comporta coma se fose o primeiro poeta que escribe nese idioma. Coidamos que non se deben tomar esas palabras ó pé da letra pois, sen dúbida ningunha, aínda que non mencione ningún autor galego no Prólogo, si sabemos que tiña cońecemento e lido o pouco que se ía publicando en galego naquela altura.

Non obstante, o modelo lingüístico oral-popular que segue Rosalía aparece arrequentado no literario polas influencias das novas sensibilidades da época. Como movemento cultural, o romanticismo trouxera xa de seu un renovado gusto por todo o popular. Xa no século XVIII algúns eruditos europeos comezaran a recoller cancións, narracións infantís e lendas populares, como en Alemaña Herder cos seus Volkslieder ou os irmáns Grimm cos seus contos. E tampouco se pode 
perder de vista que a mediados do século xIX nace o folklore como ciencia, que abranguía, segundo J. William Thoms, o investigador inglés que usou o termo por primeira vez, as chamadas «antigüidades populares» e mais a literatura popular. Precisamente, Murguía xunto con López de la Vega e Marcial Valladares serán na Galicia de mediados do século dos primeiros en recoller materiais de poesía popular. A Rosalía que frecuenta o Liceo en Santiago e que participa en actividades teatrais nesta cidade tampouco era allea a estes movementos e ideoloxías. De feito, cando a finais da década de 1850 se traslade a vivir a Madrid, vai participar da evolución e renovación das formas poéticas dese romanticismo que a literatura española está a experimentar nas voces de Ventura Pérez Aguilera, Antonio Trueba ou Augusto Ferrán, todos tres moi vinculados á publicación El Museo Universal, onde Murguía tamén era redactor. E, ó igual ca eles, Rosalía tamén vai sentir as influencias que chegan de Europa, sobre todo de Heine e tamén da balada xermánica, preocupados pola busca dunha expresión lírica análoga á poesía tradicional e por unha crecente sensibilidade cara ó popular e folclórico (Carreño 1986: 192).

E, certamente, Rosalía amosa en Cantares gallegos ter un profundo cońecemento da poesía popular galega de tradición oral, dos seus temas, das súas formas e dos seus recursos (Blanco 1992) ${ }^{5}$ e, estimulada por Murguía e escusándose no libro dos cantares de Trueba, vai artellar en 1863 un poemario aparentemente folclórico -aínda que no fondo altamente reivindicativo-, que recolle, como indica o seu propio título, cantares do país. Esta aparente fasquía folclórica estilisticamente axudaba a xustificar tamén naquela altura do século a redacción dun libro enteiro nun «dialecto rexional», e ademais nun tipo de galego que xa cualificamos de popular. Pois, como afirma Rosalía no Prólogo, tentaba precisamente reproducir o espírito do pobo, guiándose «por aqueles cantares, aquelas palabras cariñosas e aqueles xiros [...] que tan doçemente resoaron nos meus oídos desde a cuna». De por parte, a elección do rexistro popular, dun galego fiel á fala, vén xustificada grazas ó artificio literario polo cal a autora de Cantares se presenta simplemente como coleccionadora e anotadora dos versos que irá entoando unha muller do

5 Blanco (1992: 44) sinala que, probablemente, antes de escribir Cantares, Rosalía xa recollera materiais de literatura popular, entre eles varios pregos de cantares populares que, segundo Naya (1953), parecían destinados nun primeiro momento a algunha publicación de Murguía, aínda que logo algúns foron aproveitados tamén pola poeta para seren glosados en Cantares gallegos. 
pobo, «a menińa gaiteira», á que pide no primeiro poema que cante as excelencias de Galicia «na lengua gallega».

Como sinala Carreño (1986: 194), a función mimética e simbólica da linguaxe poética dos Cantares como reprodución verdadeira da lingua do pobo, con Rosalía como mediadora, xustifica igualmente unha serie de recursos literarios (o uso de retrousos, paralelismos, apóstrofes, prosopopeas, onomatopeas, repeticións, duplicacións... $)^{6}$, que veñen avalados pola lírica popular e que Rosalía renova con moderno sentido. E algo semellante vai conseguir para o dialecto «bárbaro» que dicían algúns, pois co seu simbólico libro o galego popular vai acabar obtendo carta de lingua literaria.

\section{ORALIDADE E LINGUA POPULAR EN CANTARES GALLEGOS}

As páxinas de Cantares gallegos recenden a galego oral e a galego popular. Hai oralidade, en primeiro lugar, no intento de recoller por medio de apóstrofos e guións as numerosas elisións, contraccións e asimilacións que se producen na cadea falada entre vogais e entre consoantes, fenómenos que desde a estética lingüística dos autores do Rexurdimento dotaban o galego dunha eufonía, dozura e musicalidade superior á doutras linguas ${ }^{7}$. Baixo o apóstrofo, Rosalía representou (1) contraccións xa morfolóxicas naquela altura, sobre todo nos casos de preposicións e determinantes («d' o», «n’ o», «n’ este», «d' un», «c' o»...); (2) verdadeiras elisións vocálicas en cadea por fonética sintáctica ("Qu’ antr’ os salgueiros corria»); e (3) contraccións, sobre todo de <aa> («Nunh' alborada mainiña») e mais da negación non ante forma verbal comezada por vogal («n’ hey», «n' hachara», «n’ é»...). Co guión recolleu procesos asimilatorios como o que resulta do segundo alomorfo do artigo determinado coa palabra precedente: «Qu' escorrenta-las burras», «Ti tél-o teo», ou ben grafándoo todo xunto sen guión («Tendidalas puntas»). As asimilacións entre nasais adoita representalas sen signo ningún: «No

6 Poden consultarse os principais recursos estilísticos en Lama (1986: 71-83).

7 Nese afán pola dignificación do galego como idioma melodioso, tenro, expresivo, os nosos rexudimentistas xunto ó apóstrofe sobrancearon tamén trazos coma o uso do diminutivo en -iño, a abundancia de ditongos decrecentes, o uso do pronome che ou a pronuncia branda do fonema $/ \mathrm{f} /$, fronte por exemplo a aspereza do jota castelán (vid. Hermida 1992: 136-139). 
mais», "no me», e no caso da negación non seguida de pronome átono /o, $a$, os, as/, nun caso recolle a pronuncia alveolar da nasal final da negación con guión, «no-no», e noutro representa a contracción entre as dúas unidades grafándoas unidas con acento circunflexo («nâs») e agudo («nó») $)^{8}$.

Reflíctese tamén en Cantares dun xeito case sistemático o risco do galego oral que consiste en realizar a conxunción copulativa $e$ como unha semiconsoante palatal [j] en contexto antevocálico («Y agora, miña rapaza»). Rosalía recolle este trazo fónico coa grafía $<y>$ e resulta bastante constante ó longo do texto, en concreto no $87 \%$ dos casos en que ten lugar este encontro. Así e todo, cómpre dicir que esta realización [j] é un recurso estilístico, xa que lle vale como sinalefa coa vogal seguinte e así contar unha sílaba menos. De feito, no Prólogo de Cantares, esta realización grafada $<y>$ só a utiliza en 4 dos 17 casos de contexto antevocálico («as fontes y os torrentes derramándose»); nos 13 exemplos restantes grafa <e> («recorrín á feraz Estremadura e á estensa Mancha») 9 .

Por outra parte, é tamén común no galego popular a inestabilidade das vogais átonas e de aí que se documenten nos poemas de Cantares abundantes asimilacións, moitas delas casos de harmonización vocálica con /i/ e /ei/ tónicos: inteiro, ximido, insinanzas, insina, sireixa, lisión ('lección'), direito / dereito, sirvise / servirvos, sintira / sentira, dimpois / dempois, miniña / meniña, cubirtor / cobirtor, antraberta / entraberta...; e tamén disimilacións: alomean / alumas, aspero (de 'esperar'), comprimento / cumprido, disperto, dormías / durmindo, empávedo, homildoso / humildá, malanconía, murmuxando / mormuxando, olido, polidas, romores / rumor, sofrir / sufrir, sospiros / suspiro, sotil... Como se pode ver, en moitas voces alternan formas con/sen asimilación e con/sen disimilación e, en principio, non se albisca un uso caracterizador dunhas e outras. Por poñer un

8 Nos poemas de Cantares aparecen máis de 1200 casos apostrofados. A vogal máis veces elidida é /e/, sobre todo coa conxunción que, <qu', q>, (337 casos) e a preposición de, <d'>, (267 casos), que sumados supoñen arredor do $50 \%$ dos casos. O apóstrofo como signo gráfico independente equivale ó 6 ' $6 \%$ do total de palabras, o que, xunto co uso de guións, lle dá á escrita de Rosalía (e a dos outros autores do Rexurdimento que o usaron) unha fasquía que a individualiza da escrita castelá e a achega á portuguesa, italiana ou catalá, e sobre todo á do francés, a lingua de máis prestixio da época.

9 Que esta realización como [j] é utilizada por Rosalía como recurso estilístico na poesía corrobórase tamén no uso que fai no seu Conto: os casos de $<\mathrm{e}\rangle+$ vogal suman 19 e os de $<\mathrm{y}\rangle+$ vogal só 11 . Sobre a realización da conxunción copulativa $e$ na comarca santiaguesa, Valladares (1892: 14), nativo dunha zona moi próxima a esta, advirte da súa dobre realización segundo o contexto fónico, mais indica que só os ourensáns e lugueses «suelen cambiarla en $y »$. 
exemplo, na variación dempois (27 casos) / dimpois (7 casos), Rosalía emprégaas indiferentemente cadansúa vez no poema 21 e mesmo na composición 29 usa unha e outra en estrofas seguidas (V e VI).

Tamén aparecen frecuentemente en Cantares casos de fenómenos de adición de vogais, como próteses (adivirtas, axuntan, atentalo, amostrar, abasta, arrenegado...); epénteses de iode entre vogais (doye, cheya, deseyo, feyo, soya, doyo, oya, oyen, saye.... $)^{10}$, entre consoantes (adivirtir, adimiración, adimira... ${ }^{11}$ ou por fonética sintáctica (á yalma); e paragoxes, sempre en posición de rima (amore, mare, folgare, palomare, loitare, encontrare, fervore, difícile, paise... $)^{12}$. Igualmente, ecoan fenómenos de eliminación de vogais, como aféreses (bala, de 'abalar', deprender, maxino, mañecida...), síncopas (esprito, atruxo, arbres, adresos ou pra, ben que a forma máis frecuente ó longo do texto é a plena para) e apócopes (cas, parés, quer, val..., e os curiosos casos de palabras rematadas en -axe, en que alternan por razóns métricas as apocopadas fogax, lenguax, païsáx... ${ }^{13}$ con outras plenas como ramaxe, follaxe, coraxe). As mesmas razóns métricas favorecen a escolla noutros casos entre arbores ( 2 casos) / arbres (1 caso), aderesos ( 1 caso) / adresos (1 caso), deprender (10 casos) / adeprender (2casos), quer (6 casos) / quere (1), queres (8 casos) / quès ( 1 caso), etc.

No galego oitocentista, ó igual ca no galego popular actual, o habitual é simplificar o grupo culto de dúas consoantes coa eliminación do primeiro elemento (Saco Arce 1868: 19), e así o reflicte Rosalía nos poemas en palabras como espricar, espresiós, escramar e estrańeza $([\mathrm{ks}]>[\mathrm{s}])$; en satisfación e lisión $([\mathrm{k} \theta]>[\theta]$ ou $[\mathrm{s}])$; en dina e indina $([\mathrm{gn}]>[\mathrm{n}]$; en trasparente $([\mathrm{\eta} s]>[\mathrm{s}])$; ou en perene $([\mathrm{\eta n}]$ $>[n])$. Só na voz instante non reduce o grupo [ns] e alternan as secuencias fóni-

10 Pero hai tamén voces que alternan coa non epéntese, como deseos, soa..., ou nas que nunca aparece, como en roa, ceo ou aldea.

11 Di Saco Arce en nota (1868: 20) que esta vogal epentética entre as consoantes se pronuncia moi rapidamente e compáraa coa «scheva» hebraica, isto é, que calquera das dúas pronuncias, con ou sen vogal de apoio, eran posibles.

12 Saco Arce (1868: 20-21) indica que a paragoxe ten como efecto estilístico facer máis branda a cadencia final das palabras rematadas en consoante. Sinala tamén o contexto fónico de uso: sempre cando a palabra é final de período ou se fai algunha pausa. Cando a usan escritores polo medio do verso como licenza poética, resalta o gramático ourensán que non deberá abusarse dela.

13 Saco Arce (1868: 20) alude a estes casos apocopados e indirectamente a Rosalía. Sen mencionala di que non lle parece mal a apócope como licenza poética, «con tal que no se termine con ellos el verso ó la cláusula». 
cas [nn] e [n] en conmigo (6 casos) con comigo (3 casos). No posible único caso de vocalización do primeiro elemento en direitamente, o adverbio parece estar creado a partir do adxectivo direita. Así e todo, a simplificación do grupo culto parece tamén ter un uso estilístico nos poemas como caracterizador de rexistro lingüístico, xa que no Prólogo e nos textos en prosa de rodapé de Cantares, Rosalía tende a manter o grupo culto, cando menos graficamente: dignarme, defectos, inmundo, inspiración...; só no caso de vitoria o reduce.

Documéntase así mesmo en Cantares outro trazo fónico popular, aínda hoxe operante, que consiste en adaptar as secuencias ditongais crecentes como hiatos, coma no caso de agoas ( 1 caso), coarta (1 caso), legoas (1 caso), soave(s) (9 casos) / suave (1 caso)..., que permitían á poeta sumar unha sílaba máis cando o precisaba; así e todo, no caso de váreo, varea, vareos, váreas ( 5 casos), malia a súa grafía, obriga a contar nos versos en que aparecen como ditongos, isto é bisílabos, ó igual có único caso de varia.

Recolle tamén Rosalía varios fenómenos relacionados coas consoantes líquidas /l/ e / $\mathrm{r}$, que naquela altura eran habituais no galego oral. Documenta, como tal, metáteses do / $/$ dentro da mesma sílaba (cabirto, premitan, presoas, quírtico, pirmeira, trubaban...); e trocos dunha sílaba a outra, maioritariamente da segunda para a primeira (craba, creban, crobe, cruba, frebe, probe, probiñas, recrebos; pedricadora, querbanto, trimbadoras... ${ }^{14}$. Reflicte nalgunhas palabras tamén o fenómeno de metáteses entre / / / e /l/, con cambio na linde sílabica, de xeito que ó quedar a vibrante ó inicio da sílaba esta pasa a articularse como múltiple e serve de reforzo de inicio silábico (bulrar, escalrata..., pero tamén perlas). Hai igualmente exemplos de asimiliacións e disimilacións entre estas líquidas (arbor 'albor', frol, frolear, froles, frorido, froriñas / froliñas, pelegrina, milagre...); e tamén casos de trocos entre $<\mathrm{n}>$ e $<\mathrm{r}>$ (tenra, pero tamén ternura).

Era tamén habitual no galego oral do momento que nos grupos cultos e semicultos $<\mathrm{pl} / \mathrm{pr}>,<\mathrm{bl} / \mathrm{br}>,<\mathrm{cl} / \mathrm{cr}>,<\mathrm{fl} / \mathrm{fr}>,<\mathrm{gl} / \mathrm{gr}>$ se suspendese a oposición entre $/ \mathrm{r} /$ e $/ 1 /{ }^{15}$. Rosalía recolle maioritariamente a tendencia á neutralización a favor

14 Son contados os casos de non metátese, coma este de pobreza ("Qu' é triste ó rostro da mortal pobreza»), quizais polo efecto sonoro que se consegue acompańando a triste / rostro / mortal.

15 Esta neutralización foi habitual ata hai relativamente pouco tempo no galego popular nas persoas de máis idade, como testemuñan Couceiro (1976: 34), Porto Dapena (1977: 134) e Taboada (1979: 52). 
da líquida vibrante ${ }^{16}$. Así, en Cantares son case únicos os casos de $<$ br $>$ (87 casos: branco, brancura, branda, Bras, dobran, nobresa, nubrado..., tamén nos castelanismos retembrar, niebra, robre, robreda, tiniebras...) fronte ós de <bl> (1 caso: publicalo); tamén os de <pr> (53 casos: comprace, comprimenteira, contempra, copriñas, desprumado, espricar, pranchadiñas, prantamos, temprado...) fronte ós de $<$ pl $>$ ( 9 casos: contemplar, placenteiro, plantado, resplandecente, resplandor...); os de <cr> (23 casos: crabo, crara, crarexando, craridá, mescran...) fronte a $<$ cl $>$ ( 1 caso: claro); os de <fr $>$ (41 casos: afrixido, afroxa, frol, frolear, froriñas, refrexan...) fronte a $<\mathrm{fl}>$ ( 1 caso: floriñas); e, finalmente, os casos de $<\mathrm{gr}>$ (8 casos: ygrexa, igrexińa....) fronte a ningún de $<\mathrm{gl}>$.

Canto á variación na terminación dos adxectivos de -ble / bre, a forma popular rotatizada é maioritaria nos Cantares (18 casos: agradabre, amabre, amigabre, palpabre, apacibre, culpabre / curpabre, insensibre, nobre, redobre) fronte á culta (6 casos: insensible, miserable, despreciable, imperdoable...). O número de ambas as formas equipárase no poemario máis intimista de Follas novas (vid. Monteagudo / Vilavedra 1993: 66). Alternan -bil / -ble en débil (1 caso) / deble ( 1 caso) e, por razóns de rima, Rosalía inventa a forma saudabe ('saudable') para que concorde con sabe no poema 25.

Existen, nesta predilección polas formas metatizadas e rotatizadas, motivos estilísticos, como os de conseguir efectos onomatopeicos (claramente en «Campaniñas trimbadoras», ou «e tembraba como tremban / As auguas cando fay vento»); aínda que Rosalía, igual cá maioría dos autores do Rexurdimento, busca asemade a voz diferencial co castelán, que obviamente atopa no rexistro popular.

Nas palabras procedentes das terminacións latinas -TEM, nos versos de Cantares reflíctese a alternancia que naquela altura tamén debía existir na fala entre as formas plenas en -ade ou -ude (tipo verdade, virtude) e as truncadas en -á ou -ú (tipo verdá, virtú). Así, Rosalía emprega tanto verdá / verdade e soledá / soledade. Con algunhas só aparecen formas cultas, dificultade, gravedade, propiedade ou antigüedade; e, noutras, as populares, sobriedá, mocidá, caridá, humildá, vecindá, sociedá, maxestá, segundo necesidades métricas ou de rima. Canto ás formas de plural e seguindo tamén a tendencia da oralidade, Rosalía opta por formalo maioritariamente sobre a forma plena: soledades ( 2 casos), vaïdades ( 1 caso), soidades 
(5 casos), saudades ( 2 casos) e siudades ( 1 caso). Unicamente o fai sobre a forma truncada en soidás $(3 \text { casos })^{17}$. Segundo os nosos cómputos ${ }^{18}$, nos poemas de Cantares, as formas truncadas e populares en singular ( 7 casos) gañan ás plenas ( 6 casos), en tanto que no Prólogo as únicas formas usadas son as plenas, nun claro exemplo de uso estilístico dunhas ou outras. En Follas novas, un poemario menos "popular» ca Cantares, as formas plenas en singular (52 casos) son maioritarias sobre as truncadas (42 casos) (vid. Monteagudo / Vilavedra 1993: 67).

Finalmente, cómpre comentar que Rosalía aínda emprega unha terceira terminación en -ad, en mocidad ( 1 caso) e verdad ( 2 casos). ¿Como se debe interpretar fonicamente esta grafía: á castelá, ben como [á日] ou [ád]?, ¿ou como [á], isto é, como unha variante gráfica das formas truncadas? Ó noso ver, sen descartar que sexa un simple castelanismo gráfico, pensamos que existen motivos para tratar estas formas como castelanismos morfolóxicos, pois non só aparecen en Cantares gallegos, senón que se volven rexistrar outros 7 casos en Follas novas, e 2 máis coa variante xa adaptada con seseo implosivo (eternidás e libertás), o que implica unha adaptación fónica de $[\mathrm{a} \theta]^{19}$. Os castelanismos en -ad, tipo verdad, sendo infrecuentes ${ }^{20}$, non resultan totalmente estraños nas cantigas populares ${ }^{21}$ nin noutros textos oitocentistas galegos ${ }^{22}$.

Igualmente resulta un trazo popular en Cantares, e neste caso tamén dialectal naquel tempo das falas de Santiago, Padrón e A Ulla (actualmente o fenómeno foi recuando ata a comarca fisterrá), as numerosas formas verbais contractas da $5^{\text {a }}$ persoa dalgúns tempos verbais do presente (sabés, falás, levás, balás, arrulás, atruxás, alegrás, cuspís...) e do futuro de indicativo (oirésme, dirés, dormirés,

17 Saco Arce (1868: 20) recolle a dupla posibilidade: «bondá ó bondade [...], saú ó saúde», e dá os plurais dobres "puede decirse verdás ó verdades» (1868: 31). Tamén Valladares (1892: 33) dá indiferentemente «verdá, verdade», "mercé, mercede», "quietú, quietude», ben que nos plurais só as formas en -des: «verdades, mercedes, virtudes» (1892: 31).

18 As contas de Carballo Calero (1972: 51) son diferentes ás nosas porque fai un agrupamento distinto.

19 Para outras interpretacións vid. Carballo Calero (1972: 51) e Monteagudo e Vilavedra (1993: 69-70).

20 Certamente as formas do castelán rematadas en - $d$ adaptábanse (e adáptanse) no galego tradicional, polo xeral, coa eliminación do - $d$ : por exemplo, no topónimo Madrid a acomodación máis habitual foi e é Madrí.

21 Blanco (1992) rexistra estas formas castelás no cantar: «A que veño eu cho direi / Heiche de contar verdad; veño por pasa-lo tempo, que é cousa de mocidad»; e nestoutro, "Cantade, nenas, cantade, / e deixade reír ás vellas, / qu'o tempo da mocedad / tamén o pasaron elas».

22 Nunha busca no TILG entre 1800 e 1900 rexístranse da forma castelá verdad 25 casos. 
comerés...), e mais do presente de subxuntivo (permitás, pasés, chorés...) e imperativo (coidá, andá, mirá; facéme, facé... ${ }^{23}$. As formas populares contraídas en $-s$ son moi maioritarias sobre as plenas en -de (metades, seredes e tèndes; facede, deixade), pero no imperativo compiten coas rematadas en -i: miray, buscaime, falaime, daime, levaime..., actualmente máis propias dos dialectos galegos orientais, ourensás e do sur de Pontevedra. O uso alternante dunhas e outras, incluso na mesma estrofa -coma no caso que segue da costureirińa do poema 5-, permitíalle a Rosalía o xogo estilístico de cadrar a métrica e ó tempo caracterizar lingüisticamente a personaxe: «Vos dend' arriva / Andá correndo; / Faced' os puntos, / y eu adeprendo / Andá que peno / Po-los penares... / Miray qu' ó pido / Chorando á mares». A vitalidade das formas en - s contractas e a súa convivencia e competencia coas plenas en -de nos textos galegos de finais do XvinI e principios do XIx, ben populares por outra banda, xa foi indicada por Mariño Paz (1992: 85-87), así como que tamén debían ocupar xeograficamente todo o centro e sur da provincia coruñesa e as zonas limítrofes a estas de Pontevedra e Lugo ${ }^{24}$.

Por outra banda, nos poemas 3, 5, 13 e 23 as formas tradicionais contractas da P5 (do tipo sabés, levás, facé...) aínda aparecen acompańando outro trazo sociolingüístico caracterizador dos personaxes dalgúns poemas dialogados, coma nesta estrofa do 5: «Dirés verdá, miña vella; / Mais craras as vosas niñas, / Emprestouvos, hastr' agora / Groriosa Santa Lucia». Como se ve, este tratamento de respecto co pronome vós referido a un ti esixe o emprego da segunda persoa do plural nas formas verbais (sôs), nos pronomes persoais (vos) e nos posesivos (vosas). Nestes poemas, Rosalía non fai senón testemuñar a súa vixencia, ben documentada tamén nos textos dialogados de ambiente compostelán dos primeiros decenios do século XIx (vid. Mariño Paz 2003: 127 e ss. e Álvarez 2012: 245-246). Segundo esta última investigadora, parece que foi precisamente no occidente da Coruña, entre Santiago e a costa occidental, onde permaneceu máis vivo ata os nosos días en tanto que no español e no portugués caera en desuso xa no século xviII. E

23 Algunhas destas formas contractas poderían discutirse se son segundas persoas do singular ou do plural. Lama (1995: 143 n. 3) decántase por consideralas formas de plural contractas, pero Freixeiro Mato (2000: 190-191) indica para algunha delas que son segundas do singular, como tal «Pois si vos foras pitiño» ou «Dechesmas vós, mi señora».

24 Esta alternancia na $5^{a}$ persoa está ben documentada polos nosos gramáticos oitocentistas, tanto por Saco Arce (1868: 68-69) coma por Valladares (1892: 51). 
aínda engade Álvarez que, fronte ó castelán, o emprego de vós en Galicia é sempre de respecto -mesmo dun respecto superior ó mostrado por vostede-, e sempre de inferior cara a un superior, nunca entre iguais nin con inferiores. Deste xeito o usa Rosalía, sexa esa superioridade por idade (meniña / velliña, do poema 3), status relixioso (costureiriña / santiña, do poema 5, e rapaza / San Antonio, do 13) ou clase social (namorado / fidalga castelá, do poema 23) ${ }^{25}$.

Alén disto, o tratamento de respecto conseguido co vós combínao Rosalía nestes poemas co uso de vocativos de cortesía, que poden provocar o efecto tanto de achego coma de distanciamento. Consegue a proximidade en casos coma os de miña vella, ó reforzalos estilisticamente coas formas familiares dos posesivos de primeira persoa e mais con sufixos apreciativos (miña velliña, miña Santiña, miña Santasa...), ou depreciativos (miña Santona), se o inferior non consegue o desexado ${ }^{26}$. Pola contra, o distanciamento social cada vez maior é evidente na gradación dos vocativos usados polo namorado coa señora — termo de respecto xa de seu e de claras evocacións trobadorescas_- Primeiro alúdese a ela como Castellana de Castilla, logo miña señora, despois señora, e finalmente mi señora, xa co posesivo de respecto de reminiscencia castelá e todo o que esa lingua implica canto ó status elevado na súa relación co galego. Resulta tamén significativo nese afastamento o feito de que en dúas ocasións neste poema apareza a forma castelanizada do pronome átono os (en lugar de vos): "Xa qu’ os mostrás tan ingrata» e «Si fun curpabr' en quereros».

Mais, sen dúbida, un dos trazos lingüísticos máis sobranceados na caracterización como popular do rexistro usado en Cantares gallegos é a abundancia de palabras co sufixo -iño, máis de 450 casos, ben que este número aumenta ata case 650 se contamos tamén outras palabras en -ińo, como meniño, pasesiño, camiño...,

25 Con todo, aparece un uso de vos átono de superior a inferior no caso do menińo da copla con que comeza o poema 20, "¿Quen vos ha de dar á teta, / Si tua nay vay no muhiño"; no resto, os dativos son en singular. 26 Sendo maioritario o uso de vós de respecto, nos diálogos do poema 5 ese tratamento rómpeo a "costureirińa» pasando ó ti en dúas ocasións: na primeira estrofa con fin engaiolante, e na derradeira por resentimento ó non conseguir o propósito. 
nas que non sendo morfema crean non obstante o mesmo efecto estilístico ${ }^{27}$. En porcentaxes, as palabras en -iño supoñen un $3 \%$ do total do poemario ${ }^{28}$.

Ben seguro que foi, pola expresividade e a afectividade que transmitían as palabras derivadas con el, o risco lingüístico máis ponderado polos nosos rexudimentistas para demostrar a dozura, suavidade e sonoridade do galego fronte ós que o condenaban de «bárbaro» e «rudo». Saco Arce (1868: 47) chega a afirmar que ningunha lingua usa con máis frecuencia cá nosa os diminutivos que, segundo el, «en tan íntima conformidad están con el carácter dulce e insinuante de los gallegos». E alude ó seu fonosimbolismo sinalando que «la suavidad y blandura del sonido de la ñ y la tenuidad y pequeñez de la i, hacen muy á propósito estas dos letras para espresar las ideas de cariño y ternura que juntamente con la pequeñez suelen ir anexas á los diminutivos».

E, certamente, nos numerosos exemplos de diminutivos en -iño que se documentan en Cantares, o valor predominante xa non é o orixinario de diminución, senón outros máis expresivos. Como indicou Freixeiro Mato (1996: 74), polo menos dende o século Xvir foron amoreándose sobre o nocional outros de expresividade coma os de afecto, intensificación, conmiseración, apelación, depreciativos... que é custoso de deslindar. Forte expresividade deitan estes versos do poema 15 que comezan todos con substantivos en -iño: «Téñovos, pois, que deixar, / Hortiña que tanto amei, / Fogueiriña dó meu lár, / Arborińos que prantei, / Fontińa dó cabañar». E domina, por exemplo, o intensificador do -iño nos versos: "todiñas tan ven faladas / todiñas tan entendidas», nos que pondera; e «Veñen dempois recatadas, / Anq' un pouquińo soberbias», nos que amortece. Pero comparte a idea de intensificación e de afectividade o exemplo: «Xa que te dou tan grasiosa, / Xa que te dou tan feitiña», referido a unha moza. Afecto e compaixón tamén desprenden os seguintes exemplos do poema 20: «Tremando, mal pocadiño, / Com' unha ovelliña enferma, / Sin cobirtor que te cruba / Nunhas palliñas te deitan». E imponse a función apelativa, como tal, neste caso do

27 As voces con máis de cinco ocorrencias son: meniña, -as, -o, (46), airiños (21), gaitiña (13), paxariño, -os (19), mañanciña (11), fontiña, -as (11), mihudiño (7), queridiña (7), todiños, -as (7), paseniño (6), campaniñas (5), campiños (5), pretiño (5), rosiña (5), santiña (5). En todos os poemas hai palabras en -iño, aínda que a súa frecuencia medra en «Adios rios, adios fontes» e "Airiños airiños aires».

28 Segundo as contaxes de Freixeiro Mato (1996: 143), aparece un caso de -iño cada oito versos. Deles, o $70 \%$ son substantivos, un $13 \%$ adxectivos, un $8 \%$ participios e un $6 \%$ adverbios. 
poema 3: «Desde que nasin orfiña, / De port' en porta pedindo». En fin, Rosalía espreme todos eses valores expresivos e afectivos das formas en -iño, e máis cando aparecen repetidos en versos contiguos: «Que falas tan mainiño, / Que tan mainiño andas»; e asemade se unen a outros sufixos tamén diminutivos, coma en "iQue botes tan feituquiños / Con tan feituquiñas velas!»; ou no popular recurso de repetir a mesma palabra con e sen diminutivo: «Meiguińo, meiguiño meigo, / Meigo que me namoraste», que se torna en intensificador cando son adxectivos: «Voume quedando morena, / Cal unha mouriña moura», etc. ${ }^{29}$.

É preciso, non obstante, indicar tamén neste caso que a profusión de formas co diminutivo -iño obedece a razóns estilísticas. Concordamos con Freixeiro Mato (1996) en que o seu uso non caracteriza a lingua de Rosalía de Castro, senón o estilo de Cantares gallegos, xustificado neste caso pola temática popular que aborda. Tanto é así que o seu uso case desaparece nos poemas intimistas de Follas novas de «Vaguedás» ( 2 casos) e «Do íntimo» $(6 \text { casos })^{30}$. Malia iso, neste exercicio de estilo co sufixo -iño, Rosalía conseguiu co seu xenio dotar o texto dunha naturalidade e expresividade que outros autores do seu tempo non foron quen de conseguir. De feito, non tardaron en aparecer críticas sobre o abuso que se facía del, como tal, para encher versos. Saco Arce remataba o seu artigo «Poesía contemporanea gallega. Sus defectos más comunes» (1876) recońecendo que os nomes diminutivos eran unha das peculiaridades máis características do galego a diferenza do castelán; pero aclaraba que «tales palabras son propias del estilo familiar, y que no puede sentar bien la profusión de ellas en obras de elevado carácter» (vid. Hermida 1992c: 111).

Resulta, así mesmo, outro risco da oralidade e de rexistros lingüísticos informais e familiares a variedade e abundancia de entoacións expresivas e enfáticas. Estas quedan manifestas nos Cantares, cando menos a través dos enunciados de modalidade interrogativa (58 casos) e exclamativa (350 casos), e mais polos interrompidos por medio dos puntos suspensivos (179 casos). Entre as exclamacións teñen acentuado sabor popular as que expresan valor intensificador por medio do exclamativo que antecedendo o elemento focalizado que se quere destacar, un

29 Pode verse un bo número de exemplos comentados na rigorosa análise de Freixeiro Mato (1996: 148 e ss.).

30 Como indica Feixeiro Mato (1996: 143), dunha media dun diminutivo en -iño cada oito palabras en Cantares gallegos pasamos a un cada cincuenta versos en Follas novas. 
adxectivo ou un substantivo: «QQue ricas que saben! ", «QQue feira, rapaza...!», "¿Que frescas, que polidas, que galanas», «Y aló no lar, ¡que fogo!, ¡que larada! / ¡Que rica é que ben feita frixolada!», etc. Outras co exclamativo quen cun tempo verbal de irrealidade introducen un desexo difícil de cumprir: «iQuén poidera correr mundo...», "iQuen froliña fora», "iAy, quen fora paxariño», etc. Noutros casos, os enunciados exclamativos amosan admiración: "iMoito sabés, miña vella, / Moito de sabiduría!»; mesmo compaixón: «QQue vid’ á dos probes, nena! / ¿Que vida, qu’ amarga vida»; e ás veces sorpresa: «Unha muller sin home, / ¡Santo bendito! », etc.

Pero, igualmente, esixen unha entoación enfática os versos con elementos iniciais que son foco informativo e que provocan a atracción do pronome átono á posición preverbal -pois doutro xeito esta colocación do clítico non sería gramatical en galego-: «e á quen ó mar con bramidos / Umildosos lle contesta», «Pero Vidal ó xordo se facia», "D' os meus amores che falan», «Esto che tocou, coitada», «Moita devoçon lle teño», etc.

E tamén son marcados informativamente aqueles versos en que se repite o verbo que funcionando como tópico presenta ou enmarca o tema que se vai dicir. Neste caso tralo infinitivo debe facerse pausa ou inflexión de ton ascendente $(\neg): «$ Eu cantar, cantar, cantei», «Pois por bailar, bailarían», «Por n’ ei de porche / Os meus pendentes, / Por n' ei de porche / O meu collar», "N" inda por conceder lle concedera». Saco Arce (1868: 174) destaca a enxebreza da construción indicando que constitúe «un idiotismo sobremanera usado, cuya tradución al castellano no puede ser literal, por no consentir esta lengua idéntica repetición».

En fin, outras estruturas e recursos lingüísticos axudan igualmente a caracterizar ese rexistro popular, coloquial e familiar, como a disposición da secuencia pronominal che se (“Che se volva cada día!»), que alterna estilisticamente só uns versos antes coa de se che, aínda que enclíticos (“iVolvansech” as tellas d' ouro»), variación que Saco Arce (1868: 164) testemuna dicindo que o che tanto pode ir 
antes coma despois do reflexivo se («Lixóuchese, ó lixóuseche o pano») ${ }^{31}$. E tamén contribúen a isto o uso do dativo de solidariedade che («Es' ech’ un conto», «iEste si que ch' é un porco repoludo!»...), do que Saco Arce (1868: 165) indica que é "frecuentísimo» no diálogo; a forma apocopada e contracta de mamá que aparece co posesivo de respecto como «mi máa»: "Tal maxino á sombra triste / De mi máa, soya vagando» ${ }^{32}$; a utilización do posesivo masculino plural os meus («Elas fono as que tocaron / Cand' os meus alí naceron»), no senso de 'os da miña familia’; ou a estrutura fixada por coordinación coa conxunción que baixo o esquema verbo que (te) verbo, de valor intensificador: «Dalle que dalle ó argadelo», «Porfía que te porfía», «Sempre malla que te malla», «Dempois chora que te chora», «Bate que bate, batía»...

Nas preposicións dominan tamén as formas máis populares, por outra banda diferenciais con respecto ó castelán: antre (50 casos), maioritaria fronte a entre (14); dende (6 casos), fronte a desde (2); e hastra (11 casos), fronte a hasta (1). Tamén outras coma xunta (de), que alterna con xunto de ( 4 casos), onda, que o fai nun caso con unda (con usos conxuncionais) ou cabo de. Caso á parte é a preposición para (46 casos), maioritaria na forma plena fronte á sincopada pra (2 casos nos poemas), que non obstante é a preferida por Rosalía no Prólogo e nas notas de rodapé. Nos adverbios son de tintura igualmente popular: acolá, seica/sei que, abondo, estonces, dempois/dimpois, inda/aínda, de cote, paseniño, axiña, mainamente, agora (e tamén ora/hóra), no mais ou nunca (fronte o máis formal (en) xamais, que de certo aparece nun uso grafado como jamais e noutro en jamas, polo que quizais estea utilizado estilisticamente como intensificador). Nas conxuncións sobrancea o uso exclusivo da adversativa anque, algún esporádico da causal pois que, e a temporal des que / desque, tamén desde que e ende que,

31 Segundo Álvarez (1994: 20), a secuencia che se é actualmente característica das falas das dioceses de Lugo e Ourense, como debía ser tamén no século xix conforme o testemuño de Saco Arce. Pero tampouco resulta estraña no galego santiagués das primeiras décadas do XIX, pois Mariño Paz (2003: 140-141) tamén recolle che se en dúas tertulias de ambiente compostelán e nuns versos do santiagués cura de Fruíme. Por outra banda, o carácter popular e a enxebreza desta secuencia clítica xustifican a súa presenza en textos literarios deste século, non só nos Cantares rosalianos, senón tamén nos de Fernández Neira, Leiras Pulpeiro e tamén nos non tan populares de Pintos ou Francisco de la Iglesia. En Follas novas, Rosalía volveu botar man desta concorrencia nos versos: "que a $\mathrm{i}$-augua que a beber vaias / che se volva xaramagos».

32 Non se documenta en Cantares a forma con apócope de miña, «ña madre», que si vai aparecer en Follas novas. 
en tanto que nas comparativas é maioritaria a hoxe literaria cal (tamén con usos disxuntivos), seguida de como e algún coma, que poden apostrofar.

No plano léxico crean o mesmo efecto a abondosa e expresiva adxectivación co sufixo -eiro, -a, que destaca a calidade da base sobre a que se forman: boniteiras, comprimenteira, falangueira, fidalgueiras, lagarteiro, larpeiro, mentireiras, mondongueira, parromeira, rebuldeiro... e o innúmero de voces populares e cotiás que percorren os poemas (arrular, chuchona, corrunchińo, endemocrado, garular, muchiña naviza, rebrincar, rechinar, runxir...), algunhas das cales foron listadas e comentadas no «Glosario» final que aparece no libro (vid. Pensado 1986) e outras analizadas por García (1986). E aínda reforzan ese estilo popular as expresivas comparacións que aparecen a cada paso («falás com' un abogado», "com” un-ha craba lixeira», «frío com’ á neve mesma», «alegre com’ unhas pascuas», «feito com” un santo», "calvo como San Pedro», «encarnada / com’ á color da sireixa», etc.

\section{CABO}

Dixo Cunqueiro que haberá que explicar sempre a aparición de Cantares gallegos coma un milagre. E certamente porque, sen dúbida, o gran milagre de Rosalía hai agora 150 anos foi o de converter unha lingua eminentemente oral e popular nun verdadeiro idioma literario, como dixo ela no Prólogo, «doçe e sonoro é tan a proposito com' ó pirmeiro para toda clase de versificación».

Vimos que hai en Cantares moito galego popular, pois a propia Rosalía insistiu no Prólogo que o que tentaba era reproducir a verdadeira lingua do pobo. $\mathrm{Na}$ caracterización que fixemos deste rexistro quedaron sen examinar os trazos identificadores do seu dialecto compostelán e mailas interferencias do castelán, que tamén fan parte importante deste estilo. Estas e outras características lingüísticas, xa non populares, que abrollan da poeta culta e ben cońecedora da lírica tradicional como era Rosalía de Castro examinarémolos nunha próxima contribución. 


\section{REFERENCIAS BIBLIOGRÁFICAS}

Abuín González, Anxo Uxío / Antonio Azaustre Galiana (1986): "Notas sobre o "seseo" na obra de Rosalía", en Actas do Congreso internacional de estudios sobre Rosalía de Castro e o seu tempo, Santiago de Compostela, Consello da Cultura Galega / Universidade de Santiago de Compostela, III, 99-118.

Alonso Montero, Xesús (1970): Constitución del gallego en lengua literaria. Datos de una problemática cultural y sociológica en el siglo XIX, Lugo, Celta.

Álvarez, Rosario (1994): «Gramática descritiva e gramática prescritiva», Cadernos de Lingua, 10, 19-35.

Álvarez, Rosario (2012): «Achegamento ao perfil lingüístico dos autores dos inicios da idade contemporánea», en R. Mariño Paz (ed.), Papés d'emprenta condenada II. Lingua galega e comunicación nos inicios da idade Contemporánea, Santiago de Compostela, Consello da Cultura Galega, 214-259.

Álvarez Ruiz de OJeda, Victoria (1986): Algúns aspectos da lingua galega de Rosalía de Castro. Memoria de licenciatura inédita. Santiago de Compostela.

Blanco, Domingo (1992): A poesía popular de Galicia (145-1885). Recopilación, estudio e edición crítica, I, Vigo, Xerais.

BrEA, Mercedes (1986): «As aves na poesía galega de Rosalía», en Actas do Congreso internacional de estudios sobre Rosalía de Castro e o seu tempo, Santiago de Compostela, Consello da Cultura Galega Galega / Universidade de Santiago de Compostela, III, 79-88.

Carballo Calero, Ricardo (1972): Particularidades morfológicas del lenguaje de Rosalía de Castro, Santiago de Compostela, Universidade.

Carballo Calero, Ricardo (1974): «La constitución del gallego como lengua escrita», Verba, 1, 31-40.

Carreño, A. (1986): «El discurso de la tradición: Los Cantares gallegos de Rosalía de Castro», en Actas do Congreso internacional de estudios sobre Rosalía de Castro e o seu tempo, Santiago de Compostela, Consello da Cultura Galega Galega / Universidade de Santiago de Compostela, I, 191-200.

Couceiro, José Luis (1976): El habla de Feás, Verba, anexo 5, Santiago de Compostela, Universidade.

Fernández Salgado, Benigno / Henrique Monteagudo Romero (1995): «Do galego literario ó galego común. O proceso de estandarización na época contemporánea», en H. Monteagudo (ed.), Estudios de sociolingüistica galega. Sobre a norma do galego culto, Vigo, Galaxia, 99-176.

Freixeiro Mato, Xosé Ramón (1996): Os diminutivos en galego, Vigo, A Nosa Terra.

García, Constantino (1985): Glosario de voces galegas de hoxe, Verba, anexo 27.

García, Constantino (1986): «Grilos e ralos, rans albariñas», en Actas do Congreso internacional de estudios sobre Rosalía de Castro e o seu tempo, Santiago de Compostela, Consello da Cultura Galega Galega / Universidade de Santiago de Compostela, III, 71-78.

GonzÁlez, Isabel (1986): «Os animais domésticos na poesía galega de Rosalía», en Actas do Congreso internacional de estudios sobre Rosalía de Castro e o seu tempo, Santiago de Compostela, Consello da Cultura Galega/ Universidade de Santiago de Compostela, III, 89-97.

González Seonne, Ernesto X. (2012): «Notas sobre a funcionalidade do popularismo léxico nos textos galegos do prerrexurdimento", en R. Marińo Paz (ed.), Papés d' emprenta condenada II. Lingua galega e comunicación nos inicios da Idade Contemporánea, Santiago de Compostela, Consello da Cultura Galega Galega, 261-286.

Hermida, Carme (1992a): Os precursores da normalización. Defensa e reivindicación da lingua galega no Rexurdimento (1840-1891), Vigo, Xerais. 
Hermida, Carme (1992b): A reivindicación da Lingua Galega no Rexurdimento (1840-1891). Escolma de textos, Santiago de Compostela, Consello da Cultura Galega.

Hermida, Carme (1992c): «O dialectalismo en Celso Emilio Ferreiro», en R. Álvarez (ed.) Estudios dedicados a Celso Emilio Ferreiro, Santiago de Compostela, Universidade, I, 301-316.

Lorenzo, Ramón (1986): «A lingua literaria na época de Rosalía», en Actas do Congreso internacional de estudios sobre Rosalía de Castro e o seu tempo, Santiago de Compostela, Consello da Cultura Galega Galega / Universidade de Santiago de Compostela, III, 7-41.

Mackenzie, David (1986): «A variación lingüística na obra en galego de Rosalía», en Actas do Congreso internacional de estudios sobre Rosalía de Castro e o seu tempo, Santiago de Compostela, Consello da Cultura Galega Galega / Universidade de Santiago de Compostela, III, 51-69.

Mariño PAZ, Ramón (1992): «O sufixo número-peroal da P5 en galego: o retroceso moderno da solución cantás", Cadernos de Lingua, 5, 75-97.

Mariño Paz, Ramón (2003): O idioma galego no limiar da súa renacenza, Revista Galega de Filoloxía. Monografia 2, A Coruña, Departamento de Galego-Portugués, Francés e Lingüística.

Naya Pérez, Juan (1953): Inéditos de Rosalía, Padrón, Patronato Rosalía de Castro.

Porto Dapena, José A. (1977): El gallego hablado en la comarca ferrolana, Verba, anexo 9, Santiago de Compostela, Universidade.

PociÑa Andrés / Aurora López (1993): «Introducción», en Rosalía de Castro, Poesía galega completa I, Santiago de Compostela, Sotelo Blanco, XI-LXV.

SACo ArCE, Juan Antonio (1868): Gramatica gallega, Lugo, Imprenta de Soto Freire.

Taboada, Manuel (1979): El habla del Valle de Verín, Verba, anexo 15, Santiago de Compostela, Universidade.

Valladares NúŃEz, Marcial (1970 [1892]): Elementos de Gramática Gallega, Vigo, Fundación Penzol / Editorial Galaxia.

Xove, Xosé (1986): «As formas en -ra e -se na obra poética galega de Rosalía», en Actas do Congreso internacional de estudios sobre Rosalía de Castro e o seu tempo, Santiago de Compostela, Consello da Cultura Galega Galega / Universidade de Santiago de Compostela, III, 133-149. 
